\title{
TERMOESTABILIDADE DE PROCESSOS EXTRATIVOS DE Nasturtium officinale R. Br., BRASSICACEAE POR
} SISTEMA SOXHLET MODIFICADO

\author{
João Luiz de Souza Carvalho, Miriam Machado Cunico, Josiane de Fátima Gaspari Dias*, Marilis Dallarmi Miguel e \\ Obdulio Gomes Miguel \\ Departamento de Farmácia, Universidade Federal do Paraná, Av. Prefeito Lothário Meissner, 3400, 80210-170 Curitiba - PR, \\ Brasil
}

Recebido em 6/12/07; aceito em 26/9/08; publicado na web em 2/2/09

\begin{abstract}
TERM-STABILITY OF EXTRACTIVE PROCESSES FROM Nasturtium officinale R. Br., BRASSICACEAE FOR SOXHLET MODIFIED SYSTEM. This work had as objective verified the term-stability of the Soxhlet modified system with analytical and pharmacothecnical application in extractive processes of Nasturtium officinale. It has proven that the process is thermo-stable. The analysis with analytical have determined $3.606 \mathrm{mg} \mathrm{g}^{-1}$ in chlorogenic acid and $11.813 \mathrm{mg} \mathrm{g}^{-1}$ in rutin (extract 1:20 w/v) and with pharmacotecnical $3.427 \mathrm{mg} \mathrm{g}^{-1}$ in chlorogenic acid and $11.278 \mathrm{mg} \mathrm{g}^{-1}$ in rutin (extract 1:6 w/v). The income of the pharmacothecnical process was inferior to the analytical, suggesting that the pharmacothecnical process would need of at least the double of time in each extraction system.
\end{abstract}

Keywords: thermo-stable, Soxhlet, Nasturtium officinale.

\section{INTRODUÇÃO}

Nasturtium officinale, conhecida popularmente como agrião, contém glucosinolatos (gluconasturtiin, precursor do feniletil isotiocianato e o 2-feniletilglucosinolato), ${ }^{1,2}$ nitrilas (3-fenilpropionitrila e 8-metiltiooctanona nitrila), minerais (manganês, ferro, fósforo, iodo, cobre e cálcio), vitaminas A, C, E e nicotinamida. ${ }^{1,3}$

Possui atividade antibacteriana, antiescorbútica, colagoga e propriedades expectorantes. Estudos farmacológicos demonstraram que esta espécie pode ser utilizada como protetora pulmonar de tabagistas contra agentes neoplásicos presentes no tabaco. ${ }^{1}$ Apresenta potencial cardioprotetor, ${ }^{4}$ o que justifica seu uso popular para tal fim, e atividade hipolipidêmica, que pode ser atribuída ao seu potencial antioxidante. ${ }^{5}$

Dentre os diversos processos comumente utilizados para obtenção de extratos de $N$. officinale, tem-se alcoolatura (trituração com álcool 96\%), maceração, percolação, turbólise (emprego de equipamento tipo liquidificador industrial, que pulveriza as partes vegetais e lava os conteúdos celulares) e o sistema Soxhlet, que permite a renovação do solvente sem adição de mais solvente. Estas possibilidades de extração resultam em produtos distintos quanto à qualidade $\mathrm{e}$ concentração de ativos, levando a resultados terapêuticos variáveis e diferentes custos finais. ${ }^{6}$

Dentro desta perspectiva, este trabalho teve como finalidade determinar a termoestabilidade do sistema Soxhlet, utilizando como referência dois compostos presentes no metabolismo secundário do N. officinale. ${ }^{7-9}$ Paralelamente, verificou-se o rendimento de diferentes processos de obtenção de extratos.

\section{RESULTADOS E DISCUSSÃO}

A análise preliminar realizada por meio de cromatografia em camada delgada ${ }^{6}$ com utilização de padrões demonstrou a presença de fenólicos nos extratos analisados. A termoestabilidade do sistema Soxhlet foi previamente verificada e confirmada com as posteriores análises por meio de CLAE.

*e-mail: jodias@pop.com.br
O método de CLAE utilizado para detecção simultânea dos compostos derivados do ácido clorogênico e rutina, para qualificação e quantificação nas amostras analisadas, foi validado conforme especificação da RE $n^{\circ}$ 899/03 ${ }^{10}$ - categoria I. Os dados referentes à validação encontram-se na Tabela 1 . Ao verificar a especificidade do método em dosar flavonóides em rutina e fenilpropanóides em ácido clorogênico encontram-se quantidades diferentes de resultados, pois a biblioteca da WorkStation D7000 do programa LaChrom na aquisição de dados (Reverse Library Search Results) encontrou seis estruturas relacionadas para rutina e quatro para ácido clorogênico.

As análises de CLAE realizadas nos extratos em estudo demonstraram composição rica em fenilpropanóides e flavonóides. Na Tabela 2 verificam-se os teores das substâncias analisadas nos diferentes processos extrativos. A colocação do "d-“" antes de rutina ou ácido clorogênico indica que é um "derivado de", ou seja, apresenta mais de $95 \%$ de correlação com o pico padrão e o mesmo espectro segundo biblioteca eletrônica.

A alcoolatura teve a finalidade de servir como padrão para o processo extrativo inerte, assim como para comparação da composição de analitos em estudo no vegetal in natura antes da estabilização. O material vegetal fresco apresentou $6 \%$ de rendimento em sólidos a $45{ }^{\circ} \mathrm{C}$ ou $94 \%$ de perda em água. A alcoolatura apresentou um teor de sólidos de 1,06\% ou 7,42 g de sólidos nos $700 \mathrm{~mL}$ e 3,18 g de sólidos extraíveis nos $300 \mathrm{~mL}$ de alcoolatura impregnados no resíduo, perfazendo uma massa total de 10,6 g de extraíveis em 500 g (1000 $\mathrm{mL}$ de alcoolatura) de $N$. officinale in natura. Considerando-se $30 \mathrm{~g}$ de massa seca das $500 \mathrm{~g}$ de $N$. officinale in natura (6\% de sólidos) obteve-se rendimento de $35,33 \%$ de sólidos da composição extraída (Tabela 3) e 0,673 $\mathrm{mg} \mathrm{g}^{-1}$ de fenólicos calculados em ácido clorogênico e rutina (Tabela 2).

Na extração por dupla maceração, o extrato bruto de $N$. officinale apresentou $67 \%$ da solução extratora e os $33 \%$ restantes permaneceram no resíduo. A massa de sólidos extraída nas $500 \mathrm{~g}$ de planta foi de $110 \mathrm{~g}$ ou $22 \%$ de sólidos da composição extraída (Tabela 3) e $9,381 \mathrm{mg} \mathrm{g}^{-1}$ de fenólicos calculados em ácido clorogênico e rutina (Tabela 2). 
Tabela 1. Resultados das análises realizadas para validação da metodologia - doseamento de flavonóides em rutina e fenilpropanóides em ácido clorogênico

\begin{tabular}{|c|c|c|c|c|c|}
\hline \multicolumn{2}{|c|}{ Parâmetro Analisado } & \multicolumn{2}{|c|}{ Especificação } & $\begin{array}{l}\text { Doseamento de } \\
\text { flavonóides em rutina }\end{array}$ & \multirow{2}{*}{$\begin{array}{c}\text { Doseamento de } \\
\text { fenilpropanóides em } \\
\text { ácido clorogênico }\end{array}$} \\
\hline \multirow{14}{*}{ Especificidade } & Influência dos excipientes & $\begin{array}{r}\text { Os excipien } \\
\text { no dose }\end{array}$ & $\begin{array}{l}\text { m interferir } \\
\text { analitos }\end{array}$ & Conforme & \\
\hline & \multirow{6}{*}{ Pureza dos picos } & \multirow{6}{*}{\multicolumn{2}{|c|}{ Mínimo 99\% }} & $99,96 \%(\operatorname{tr} 24,70)$ & $99,19 \%(\operatorname{tr} 20,70)$ \\
\hline & & & & $99,88 \%(\operatorname{tr} 37,20)$ & $99,26 \%(\operatorname{tr} 22,50)$ \\
\hline & & & & $99,23 \%(\operatorname{tr} 38,40)$ & $99,97 \%(\operatorname{tr} 27,70)$ \\
\hline & & & & $99,53 \%(\operatorname{tr} 40,70)$ & $99,89 \%(\operatorname{tr} 24,27)$ \\
\hline & & & & $99,34 \%(\operatorname{tr} 42,00)$ & $99,57 \%(\operatorname{tr} 43,20)$ \\
\hline & & & & $99,57 \%(\operatorname{tr} 43,20)$ & \\
\hline & \multirow{6}{*}{ Correlação com pico padrão } & \multirow{6}{*}{\multicolumn{2}{|c|}{ Mínimo 95\% }} & $98,31 \%(\operatorname{tr} 24,70)$ & $96,11 \%(\operatorname{tr} 20,70)$ \\
\hline & & & & $98,67 \%(\operatorname{tr} 37,20)$ & $96,13 \%(\operatorname{tr} 22,50)$ \\
\hline & & & & $96,65 \%(\operatorname{tr} 38,40)$ & $99,45 \%(\operatorname{tr} 27,70)$ \\
\hline & & & & $98,18 \%(\operatorname{tr} 40,70)$ & $99,54 \%(\operatorname{tr} 24,27)$ \\
\hline & & & & $97,70 \%(\operatorname{tr} 42,00)$ & \\
\hline & & & & $98,18 \%(\operatorname{tr} 43,20)$ & \\
\hline & Fingerprint & \multicolumn{2}{|c|}{$\begin{array}{c}\text { As amostras possuem o mesmo } \\
\text { perfil cromatográfico }\end{array}$} & \multicolumn{2}{|c|}{ Conforme } \\
\hline Linearidade & Curva & \multicolumn{2}{|c|}{$\mathrm{r}^{2} \geq 0,99$} & \multicolumn{2}{|c|}{$\mathrm{r}^{2}=0,9966$} \\
\hline \multirow{3}{*}{ Precisão } & \multirow{2}{*}{ Repetibilidade } & \multirow{2}{*}{$\mathrm{DPR} \leq 5 \%$} & Analista 01 & $\mathrm{DPR}=1,43 \%$ & $\mathrm{DPR}=1,38 \%$ \\
\hline & & & Analista 02 & $\mathrm{DPR}=1,59 \%$ & $\mathrm{DPR}=1,45 \%$ \\
\hline & Intermediária & \multicolumn{2}{|c|}{$\mathrm{DPR} \leq 5 \%$} & $\mathrm{DPR}=1,71 \%$ & $\mathrm{DPR}=1,66 \%$ \\
\hline \multirow{3}{*}{ Exatidão } & Adição de padrões & \multirow{3}{*}{$\begin{array}{l}\text { Recuperação } \\
95 \text { a } 105 \%\end{array}$} & Conc $80 \%$ & $102,80 \%$ & $99,67 \%$ \\
\hline & & & Conc $100 \%$ & $99,57 \%$ & $101,31 \%$ \\
\hline & & & Conc $120 \%$ & $99,32 \%$ & $100,96 \%$ \\
\hline \multirow{3}{*}{ Robustez } & Composição da fase móvel & & & \multicolumn{2}{|c|}{$\mathrm{DPR}=0,19 \%$} \\
\hline & Troca de coluna & \multicolumn{2}{|c|}{$\mathrm{DPR} \leq 5 \%$} & \multicolumn{2}{|c|}{$\mathrm{DPR}=1,21 \%$} \\
\hline & Estabilidade da solução final & \multicolumn{2}{|c|}{$\mathrm{DPR} \leq 5 \%$} & \multicolumn{2}{|c|}{$\mathrm{DPR}=3,78 \%$} \\
\hline
\end{tabular}

$\mathrm{DPR}=$ desvio padrão relativo, $\operatorname{tr}=$ tempo de retenção, $\mathrm{r}^{2}=$ coeficiente de correlação e conc $=$ concentração segundo ANVISA.

Tabela 2. Teores em fenólicos de ácido clorogênico e rutina na análise de CLAE em amostras de $N$. officinale obtidas por diferentes processos extrativos

Nasturtium officinale

Alcoolatura (mg/g) Dupla maceração $(\mathrm{mg} / \mathrm{g}) \quad$ Soxhlet analítico $(\mathrm{mg} / \mathrm{g}) \quad$ Soxhlet farmacotécnico $(\mathrm{mg} / \mathrm{g})$

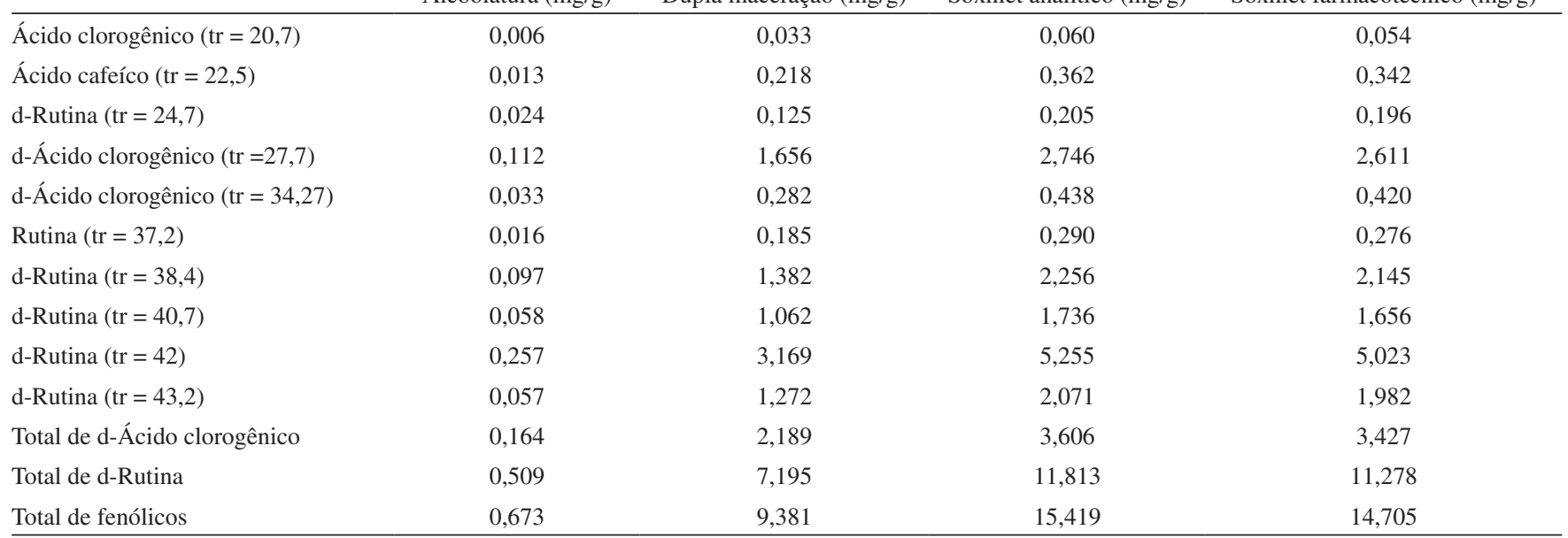

d- = derivado de; $\operatorname{tr}$ = tempo de retenção em relação à especificidade ou de ácido clorogênico ou rutina. 
A extração em Soxhlet modificado com aplicação farmacotécnica obteve $1000 \mathrm{~mL}$ de extrato, com teor de $34,25 \%$ de sólidos da composição extraída (Tabela 3) e 14,705 $\mathrm{mg} \mathrm{g}^{-1}$ de fenólicos calculados em ácido clorogênico e rutina (Tabela 2).

Os extratos obtidos por dupla maceração e Soxhlet farmacotécnico tiveram a finalidade de simular o processo industrial. Os sistemas convencionais trabalham geralmente com maceração a frio desconsiderando os efeitos de solvatação, saturação do solvente com a constante de solubilização da composição química do vegetal a quente.

A extração em Soxhlet analítico modificado teve a finalidade de permitir o esgotamento total de extraíveis da droga para comparar a composição, fórmula percentual e o teor total dos analitos em estudo. Verificou-se um teor de 35,23\% de sólidos da composição extraída (Tabela 3) e 15,419 $\mathrm{mg} \mathrm{g}^{-1}$ de fenólicos calculados em ácido clorogênico e rutina (Tabela 2 ).

Para verificação da termoestabilidade, preparou-se amostra padrão com ácido clorogênico e rutina em amido pelo processo Soxhlet modificado analítico e verificou-se por CLAE que $99,1 \%$ do ácido clorogênico e rutina adicionados no amido foram recuperados e não se detectou compostos da decomposição ou stress térmico do processo. Na extração do ácido clorogênico e rutina adicionados no material vegetal seco, obteve-se 99,3\% de recuperação, sem apresentar compostos da decomposição no processo e inércia química com a composição do agrião pelo processo Soxhlet modificado analítico.

Todos os processos empregados no presente estudo apresentaram a mesma composição da alcoolatura utilizada como padrão e os processos Soxhlet reproduziram a mesma fórmula percentual de extraíveis, devido ao esgotamento total dos compostos.

$\mathrm{Na}$ Figura 1 verifica-se a especificidade do fingerprint entre as amostras e os padrões desta metodologia.

\section{PARTE EXPERIMENTAL}

\section{Material vegetal}

O material vegetal foi coletado em dezembro de 2005, identificado pelo Dr. G. Hatschbach e registrado no Museu Botânico de Curitiba sob o número 248503. Este material vegetal foi pré-estabilizado em condições ambientes e estabilizado em estufa ventilada a $45^{\circ} \mathrm{C}$, por um período de $20 \mathrm{~h}$. A padronização granulométrica foi realizada em um moinho de facas, com tamis de $8 \mathrm{~mm}$.

\section{Condições cromatográficas}

Todos os reagentes e solventes foram adquiridos em grau P.A. ou HPLC $\left(\right.$ Merck $\left.^{\circledR}\right)$. A água utilizada no preparo das soluções foi obtida por sistema de purificação e filtração Milli-Q (Millipore ). Os padrões de ácido clorogênico e rutina utilizados foram adquiridos da Sigma ${ }^{\circledR}$.

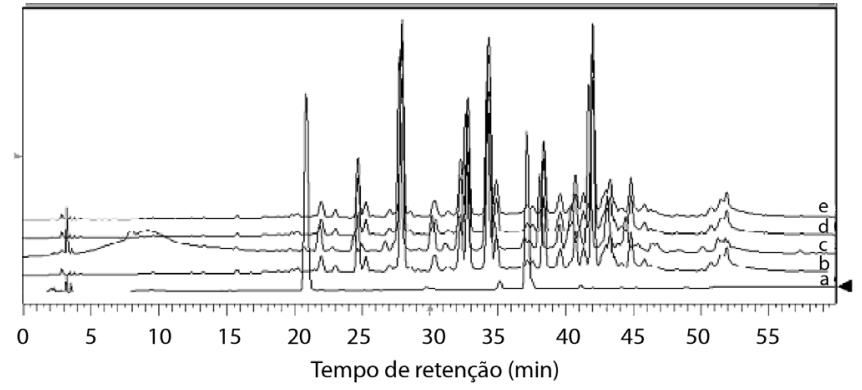

Figura 1. Multicromatograma do fingerprint entre as amostras e o padrão, onde (a) padrões de ácido clorogênico e rutina; (b) amostra da alcoolatura; (c) amostra do extrato obtido por dupla maceração; (d) amostra do extrato obtido por Soxhlet modificado analítico; (e) amostra do extrato obtido por Soxhlet modificado farmacotécnico

A análise qualitativa preliminar foi realizada por meio de cromatografia em camada delgada, utilizando-se cromatoplacas de sílica gel $\mathrm{F}_{250}\left(\mathrm{Merck}^{\circledR}\right)$, de dimensões $10 \mathrm{~cm}$ por $10 \mathrm{~cm}$, onde $10 \mu \mathrm{L}$ de cada amostra foi aplicada, intercalando com referências solubilizadas em metanol $\left(1 \mathrm{mg} \mathrm{mL}^{-1}\right)$. As fases móveis e seus respectivos reveladores foram utilizados de acordo com a literatura. ${ }^{6,11}$

As análises qualitativas e quantitativas foram realizadas por cromatografia líquida de alta eficiência (CLAE), em aparelho Merck-Hitashi ${ }^{\circledR}$ composto de bomba L7100, degaseificador de solventes L7812, válvula de injeção Rheodyne ${ }^{\circledR} 7725$ i com loop de $20 \mu \mathrm{L}$, forno L-7300, detector DAD L7450, em $325 \mathrm{~nm}$ para ácido clorogênico e $350 \mathrm{~nm}$ para a rutina, interface $\mathrm{L} 7000$ conectada ao sistema operacional Windows ${ }^{\circledR}$ NT e tratamento dos dados pela ChemiStation Lachrom ${ }^{\circledR}$. Utilizou-se a coluna analítica Phenomenex $\mathrm{C}_{18}(4$ x $250 \mathrm{~mm}, 5 \mu \mathrm{m})$.

A metodologia empregada para análise foi desenvolvida por Carvalho ${ }^{6}$ e validada de acordo com a resolução 899 de 29 de maio de 2003 da ANVISA (metodologia enquadrada na categoria I - validação de método analítico quantitativo para uma substância entre outros componentes $)^{10}$ e foi otimizada para fenólicos, ${ }^{6,12,13}$ num gradiente ternário, utilizando como fase móvel A 0,2\% de ácido fosfórico em ácido sulfúrico $0,01 \mathrm{M}$, fase móvel $\mathrm{B}$ metanol e fase $\mathrm{C}$ acetonitrila. $\mathrm{O}$ gradiente de eluição foi: $0-3$ min a $1,2 \mathrm{~mL} \mathrm{~min}^{-1}$ de fluxo com $100 \%$ A; 3-5 min a $1,2 \mathrm{~mL} \min ^{-1}$ de fluxo para $7 \%$ B e 3\% C; 5-15 min a $1,2 \mathrm{~mL} \mathrm{~min}^{-1}$ de fluxo para $16 \% \mathrm{~B}$ e $3 \% \mathrm{C} ; 15-40 \mathrm{~min}$ a $1,2 \mathrm{~mL} \mathrm{~min}^{-1}$ de fluxo para $26 \%$ B e $15 \% \mathrm{C}$; $40-47 \mathrm{~min}$ a $1,3 \mathrm{~mL} \mathrm{~min}^{-1}$ de fluxo para $26 \% \mathrm{~B}$ e $15 \% \mathrm{C} ; 47-48 \mathrm{~min}$ a $1,3 \mathrm{~mL} \mathrm{~min}^{-1}$ de fluxo para $30 \%$ B e $30 \% \mathrm{C}$; $48-54 \mathrm{~min}$ a $1,3 \mathrm{~mL} \mathrm{m^{-1 }}$ de fluxo para $30 \%$ B e $30 \% \mathrm{C}$; 55-60 min a $1,2 \mathrm{~mL} \mathrm{~min}^{-1}$ de fluxo para $100 \% \mathrm{~A}$.

A identificação dos compostos foi realizada pela ChemiStation Lachrom $^{\circledR}$ com base nos tempos de retenção das amostras e comparação com os tempos dos padrões, dados de literatura e de seus espectros introduzidos na biblioteca eletrônica (Reverse Library Search Results). ${ }^{6,14-16}$

Tabela 3. Teor de sólidos obtidos nos processos de extração do Nasturtium officinale

\begin{tabular}{lccccccc}
\hline $\begin{array}{l}\text { Processo de } \\
\text { extração }\end{array}$ & $\begin{array}{c}\text { massa de planta } \\
(\mathrm{g})\end{array}$ & $\begin{array}{c}\text { volume etanol } \\
\text { adicionado }(\mathrm{mL})\end{array}$ & $\begin{array}{c}\text { volume final } \\
(\mathrm{mL})\end{array}$ & $\begin{array}{c}\text { massa de sólidos } \\
(\mathrm{g})\end{array}$ & $\begin{array}{c}\text { \% sólidos } \\
\text { no extrato }\end{array}$ & $\begin{array}{c}\text { \% sólidos } \\
\text { na planta }\end{array}$ & $\begin{array}{c}\text { rendimento } \\
(35,33=100 \%)\end{array}$ \\
\hline Alcoolatura & 500 & 530 & $700\left(300^{* *}\right)$ & $7,42\left(3,18^{*}\right)$ & 1,06 & $2,12(35,33 * * *)$ & $70(30=$ perda $)$ \\
Dupla maceração & 500 & 1500 & 1000 & 110 & 11 & 22 & 62,3 \\
Analítico & 10 & 200 & 100 & 3,53 & 3,53 & 35,23 & 99,7 \\
Farmacotécnico & 500 & 3000 & 1000 & 171,5 & 17,15 & 34,25 & 96,9 \\
\hline
\end{tabular}

* = perda de sólidos no resíduo da alcoolatura, $* *$ = perda no resíduo de alcoolatura, $* * *$ = referência de esgotamento. 
Para a construção da curva analítica da solução padrão ${ }^{6,12,13}$ foram utilizados níveis de concentração em ácido clorogênico sendo 5, 10, 20,40, 45, 5055 e $60 \mu \mathrm{g} \mathrm{mL}^{-1}$ e rutina com 10, 20, 40, 80, 90, 100, 110 e $120 \mu \mathrm{g} \mathrm{mL}^{-1}$ segundo norma. ${ }^{10}$

Os processos de extração foram comparados com dois grupos fenólicos, fenilpropanóides com ácido clorogênico (2) e flavonóides com rutina ${ }^{14,17,18}(\mathbf{1})$. Para o preparo da solução padrão com ácido clorogênico e rutina, adicionou-se $20 \mathrm{mg}$ de ácido clorogênico e 40 $\mathrm{mg}$ de rutina em um balão volumétrico de $100 \mathrm{~mL}$ e seu volume foi completado com etanol 85\%.6,9,10 Para análise por CLAE, as amostras de padrões foram diluídas com solução mista da fase móvel A:fase móvel B (1:1 v/v) e co-injetadas em todas as análises dos processos de extração.<smiles>CCOc1c(-c2ccc(O)c(O)c2)oc2cc(O)cc(O)c2c1=O</smiles><smiles>O=C(O)C1(O)CC(O)C(O)C(OC(O)C=Cc2ccc(O)c(O)c2)C1</smiles>

(2)

Figura 2. Fórmulas estruturais - rutina (1) e ácido clorogênico (2)

\section{Métodos de extração e análises}

As extrações foram realizadas com solventes P.A. e em triplicata.

\section{Alcoolatura e dupla maceração}

Para a obtenção de alcoolatura foram triturados, por $2 \mathrm{~min}, 500 \mathrm{~g}$ da planta inteira fresca e $550 \mathrm{~mL}$ de etanol a $96 \%$. Em seguida, esta solução foi submetida a uma maceração a frio, por $72 \mathrm{~h}$ e filtração a vácuo. A preparação da alcoolatura foi realizada de acordo com normas estabelecidas pela farmacopéia. ${ }^{15,16} \mathrm{~A}$ alcoolatura foi concentrada, onde $250 \mathrm{~mL}$ foram concentrados para $40 \mathrm{~mL}$ e seu volume ajustado para $50 \mathrm{~mL}$ com etanol a $85 \%$.

Para extração por dupla maceração, $500 \mathrm{~g}$ do material vegetal foram maceradas em $1000 \mathrm{~mL}$ de etanol 85\% (850 mL de etanol $96 \%$ e $150 \mathrm{~mL}$ de água) em um percolador de $3 \mathrm{~L}$. Após $72 \mathrm{~h}$, procedeu-se à eluição que resultou na obtenção da primeira fração de $500 \mathrm{~mL}$ do extrato. O resíduo foi novamente extraído por maceração, durante 72 h, após adição de $500 \mathrm{~mL}$ de etanol $85 \%$, produzindo a segunda fração de $500 \mathrm{~mL}$ do extrato. Pela reunião destas duas frações foram obtidos $1000 \mathrm{~mL}$ de extrato bruto etanólico.

O teor de sólidos da alcoolatura e da dupla maceração foi determinado por meio de perda por estufa a $45^{\circ} \mathrm{C}$, por $3 \mathrm{~h}$, utilizando-se uma alíquota de $10 \mathrm{~mL}$ de amostra, em triplicata. Para análise de fenólicos por CLAE, $500 \mu \mathrm{L}$ de alcoolatura e $300 \mu \mathrm{L}$ da dupla maceração foram diluídos em 500 e $900 \mu \mathrm{L}$, respectivamente, em solução mista de fase móvel A e fase móvel B (1:1 v/v) em tubo Eppendorf de 1,5 mL.

\section{Soxhlet modificado farmacotécnico}

No Soxhlet modificado com aplicação farmacotécnica, há substituição do sistema de percolação por uma placa de teflon perfurada
(Figura 3) e recoberta com algodão, com o objetivo de filtrar a solução extratora eluída.

Foram adicionados $500 \mathrm{~g}$ de material vegetal no extrator, $1500 \mathrm{~mL}$ de etanol 85\% sobre o material vegetal para umectação (por 30 min) e $1500 \mathrm{~mL}$ de etanol a $85 \%(1275 \mathrm{~mL}$ de etanol $96 \%$ e $225 \mathrm{~mL}$ de água) no balão de fundo chato (para conexão com o sistema Soxhlet, utiliza-se balão com junta 24/40 ou 29/42). O processo de extração foi mantido por $5 \mathrm{~h}$ (para conexão com o condensador, utiliza-se junta $71 / 60$ ). Em seguida, concentrou-se o extrato do balão para aproximadamente $800 \mathrm{~mL}$. O extrato foi transferido para um balão volumétrico e completado o volume com etanol (85\%) para $1000 \mathrm{~mL}$.

O teor de sólidos dos extratos foi determinado por meio de perda por estufa a $45^{\circ} \mathrm{C}$ por $3 \mathrm{~h}$, utilizando alíquota de $10 \mathrm{~mL}$ de amostra, em triplicata.

Para análise de fenólicos por CLAE, $150 \mu \mathrm{L}$ de amostra foram diluídas em $1350 \mu \mathrm{L}$ de solução mista de fase móvel A e fase móvel B (1:1 v/v) em tubo Eppendorf de 1,5 mL.
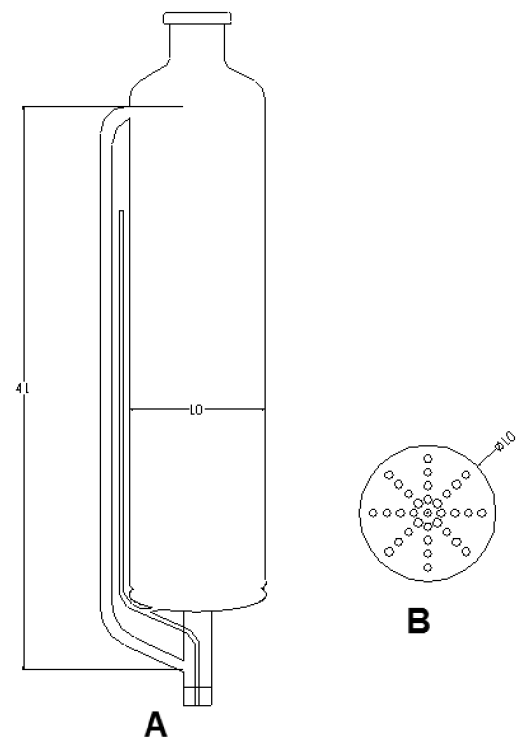

Figura 3. Soxhlet modificado farmacotécnico, onde $A=\operatorname{sistema~Soxhlet~}(10 \mathrm{~cm}$ de diâmetro e $41 \mathrm{~cm}$ de altura) e $B=$ placa de teflon (10 cm de diâmetro)

\section{Soxhlet analítico modificado}

A preparação do extrato analítico foi feita adicionando-se $10 \mathrm{~g}$ do material vegetal num cartucho de vidro tipo Pyrex ${ }^{\circledR}$ com base de vidro sinterizado G3 (Figura 4), $50 \mathrm{~mL}$ de etanol 85\% (85 mL de etanol $96 \%$ e $15 \mathrm{~mL}$ de água) deixando o sistema em repouso por $30 \mathrm{~min}$, para umectação da droga. Em seguida, $150 \mathrm{~mL}$ de etanol $85 \%$ foram adicionados ao balão de fundo chato (para conexão com o sistema Soxhlet, utiliza-se balão com junta 24/40) e conectou-se ao extrator. Esse procedimento ficou ativo por $4 \mathrm{~h}$ (para conexão com o condensador, utiliza-se junta 45/50). O extrato obtido foi concentrado para $80 \mathrm{~mL}$ e seu volume completado para $100 \mathrm{~mL}$ com etanol $85 \%$.

O teor de sólidos dos extratos foi determinado por meio de perda por estufa a $45^{\circ} \mathrm{C}$ por $3 \mathrm{~h}$, utilizando alíquotas de $10 \mathrm{~mL}$ de amostra, em triplicata.

Para o preparo da amostra padrão, os padrões, ácido clorogênico e rutina foram extraídos em Soxhlet modificado com aplicação de 20 $\mathrm{mg}$ de ácido clorogênico e $40 \mathrm{mg}$ de rutina num cartucho de vidro tipo Pyrex ${ }^{\circledR}$ com base de vidro sinterizado G3, contendo $10 \mathrm{~g}$ de amido. Foram adicionados $50 \mathrm{~mL}$ de etanol (85\%) deixando o sistema em repouso por $30 \mathrm{~min}$, para umectação do material vegetal. Em seguida, $150 \mathrm{~mL}$ de etanol $85 \%$ foram adicionados ao balão de fundo chato e conectou-se ao extrator. Esse procedimento ficou ativo por $4 \mathrm{~h}$. O 
extrato obtido foi concentrado para $80 \mathrm{~mL}$ e seu volume completado para $100 \mathrm{~mL}$ com etanol (85\%).

Para verificação da inércia e termoestabilidade, $10 \mathrm{~g}$ de material vegetal, $20 \mathrm{mg}$ de ácido clorogênico e $40 \mathrm{mg}$ de rutina foram utilizados em processo idêntico ao de preparação do extrato analítico e amostra padrão. Para análise de fenólicos por CLAE, $300 \mu \mathrm{L}$ de amostra padrão, $500 \mu \mathrm{L}$ do extrato analítico e $300 \mu \mathrm{L}$ de extrato, para verificação da inércia e termoestabilidade, foram diluídos em 900, 500 e $900 \mu \mathrm{L}$, respectivamente, em solução mista de fase móvel A e fase móvel B $(1: 1 \mathrm{v} / \mathrm{v})$ da CLAE, em tubo Eppendorf de 1,5 mL.

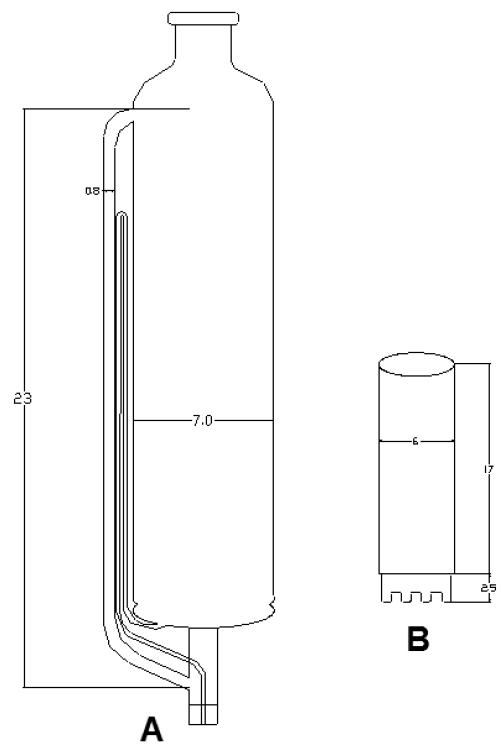

Figura 4. Soxhlet analítico modificado, onde $A=$ sistema Soxhlet $(7 \mathrm{~cm}$ de diâmetro e $23 \mathrm{~cm}$ de altura) e $B=$ cartucho de vidro com base de vidro sinterizado $G 3$ (6 cm de diâmetro e $19,5 \mathrm{~cm}$ de altura - destes, 2,5 cm correspondem à altura da base)

\section{CONCLUSÕES}

Neste trabalho verificou-se a termoestabilidade no sistema Soxhlet modificado, ou seja, no processo extrativo não ocorreu variação da composição do mesmo, com o efeito da temperatura. A termoestabilidade foi avaliada por CLAE e o teor de fenólicos, calculado em ácido clorogênico e rutina, comprovou que o processo é termoestável ao efeito da temperatura e que atende às normas da ANVISA. Este processo mostrou-se limpo, rápido, reprodutível e com alto rendimento em extraíveis em relação ao teor de sólidos, apresentando no extrator o resíduo do material vegetal incorporado com o etanol destilado do final do processo.
No processo analítico obteve-se 35,23\% de sólidos a partir de 10 g de planta para $200 \mathrm{~mL}$ de solvente extrator (1:20) e no farmacotécnico, $34,25 \%$ de sólidos a partir de $500 \mathrm{~g}$ para $3000 \mathrm{~mL}$ de solvente extrator (1:6). Isto sugere que o processo farmacotécnico necessitaria de pelo menos o dobro de tempo em cada sistema de extração para se equiparar ao analítico, tornando-se inviável em custo de energia e tempo disponível do equipamento e na utilização industrial, devido ao custo final do produto.

\section{AGRADECIMENTOS}

Aos colaboradores H. Dias Jr. e F. S. F. Smolarek, ao Departamento de Farmácia da Universidade Federal do Paraná e ao CNPq.

\section{REFERÊNCIAS}

1. Blumenthal, M.; Goldberg, A.; Brinckmann, J.; Herbal Medicine - Integrative Medicine Communications, $1^{\text {st }}$ ed., American Botanical Council: Austin, 2000

2. Gil, V.; Macleod, A-J.; Phytochemistry 1980, 19, 1657.

3. Loggia, R. D.; Piante Officinali per Infusi e Tisane, $3^{\text {rd }}$ ed., Organizzazione Editorale Medico Farmacêutica: Milano, 1993.

4. Bahramikia, S.; Yazdanparast, R.; J. Ethnopharmacol. 2008, 4, 115.

5. Yazdanparast, R.; Bahramikia, S.; Ardestani.; A.; Chem. Biol. Interact. 2008, 172, 176 .

6. Carvalho, J. L. S.; Dissertação de Mestrado, Universidade Federal do Paraná, Brasil, 2001.

7. Katalinic, V.; J. Chromatogr. 1997, 775, 359.

8. Anterola, A. M.; Lewis, N. G.; Phytochemistry 2002, 61, 221.

9. Engelen-Eigles, G.; Holden, G.; Cohen, J. D.; Gardner, G.; J. Agric. Food Chem. 2006, 54, 328.

10. http://e-legis.anvisa.gov.br/leisref/public/showAct.php?id=15132\&word=, acessada em Julho 2007.

11. Wagner, H.; Bladt, S.; Plant Drugs Analysis, $2^{\text {nd }}$ ed., Springer-Verlag: Berlin, 2001.

12. Alves, S. T.; Dias, R. C. E.; Benassi, M. T.; Scholz, M. B. S.; Quim. Nova 2006, 29, 1164.

13. Ribani, M.; Bottoli, C. B. G.; Collins, C. H.; Jardim, I. C. S. F.; Melo, L. F. C.; Quim. Nova 2004, 27, 771.

14. Mabry, T. J. ; Markham, K. R.; Thomas, M. B.; The Systematic Identification of Flavonoids, Springer-Verlag: Berlin, 1970.

15. Farmacopéia Brasileira, $2^{\text {a }}$ ed., Indústria Gráfica Siqueira: São Paulo, 1959.

16. Farmacopéia Brasileira, 4a ed., Atheneu: São Paulo, 1988-1996.

17. Burns, J.; Fraser, P. D.; Bramley, P. M.; Phytochemistry 2003, 62, 939.

18. http://www.drastic.org.uk, acessada em Julho 2006. 